Journal of Engineering and Applied Sciences 15 (5): 1082-1088, 2020

ISSN: 1816-949X

(C) Medwell Journals, 2020

\title{
Experimental and Computational Study of the Structure on Selected Species Mineralogical of Kaolins in the Union (Antioquia), Colombia
}

\author{
${ }^{1}$ M. Oswaldo Bustamante, ${ }^{2}$ Andrés M. Muñoz-Garcia, ${ }^{3}$ Martin E. Espitia, ${ }^{2}$ Luis F. Duque, \\ ${ }^{2} \mathrm{C}$. Valencia-Balvin and ${ }^{2} \mathrm{~S}$. Perez-Walton \\ ${ }^{1}$ Facultad de Minas, Universidad Nacional de Colombia, Medellín, Colombia \\ ${ }^{2}$ Instituto Tecnologico Metropolitano de Medellín, Medellín, Colombia \\ ${ }^{3}$ Facultad de Ingeniería, Corporacion Universitaria Minuto de Dios, Bogotá, Colombia
}

\begin{abstract}
In this research, both an experimental and computational study of the mineralogical structures of some kaolin samples are shown. The kaolin samples come from La Union, located in Antioquia, Colombia. The experimental study was carried out by X-Ray Fluorescence (XRF), X-Ray Difraction (XRD), Mossbauer spectroscopy and colorimetric analysis, so, it was possible to measure an elementary components amount and some morphological characteristics that include cell parameters and atomic positions. In the other hand by ab-inito computational methods it was possible to identify crystallographic characteristics which lead to predict some physical and chemical properties at different conditions. The simulation was performed using VASP Software, taking in account experimental results as starting data. The study of the relationship between physical and chemical properties and the crystallographic structure of kaolin is important in order to understand some phenomena related to hydrometallurgy, state solid physics and computational mineralogy because it leads to improve the yield of clay and non-metallic materials processing which are part of Colombian economy.
\end{abstract}

Key words: Kaolins, species mineralogical, crystal structure, ab-initio, VASP Software, morphological

\section{INTRODUCTION}

Kaolin is an industrial mineral widely used in Colombia as a raw material in the ceramic industry, paint and cement among others. From the geologic standpoint, the kaolin refers to the argillaceous rock dominated by minerals of Kaolinite group, although, it is usually also be composed of other minerals such as: quartz, sulphides, feldspars, micas, iron oxides and oxides of titanium and other minerals in clay, Montmorillonite, illite, smectite or a possible combination with one or more of these (Benea and Gorea, 2004).

The white colour of the kaolin is one of the main characteristics by which is used in many industrial applications and its use requires some specifications of brightness and whiteness (Murray, 1963). The whiteness of this rock is affected by the presence of iron minerals adsorbed on the surface; these minerals such as hematite $\left(\mathrm{Fe}_{2} \mathrm{O}_{3}\right)$, goethite $(\mathrm{FeO}(\mathrm{OH}))$, ilmenite $\left(\mathrm{FeTiO}_{2}\right)$ and others are independent of colloidal size and nanometric crystalline phases (Chandrasekhar and Ramaswamy, 2006).

In general, the industrial use of kaolin, involves separation of this type of contaminants in many cases by methods of extractive metallurgy such methods can be classified into physical and chemical or a combination of both (Clark et al., 1962; Conley and Lloyd, 1970; Gonzalez and Ruiz, 2006; Chandrasekhar and Ramaswamy, 2002). The Colombian industry uses for these purposes, a process known as chemical bleaching that achieves a selective dissolution of iron compounds adsorbed on the mineral surface by a reducing agent (Conley and Lloyd, 1970).

Studies reported by national and international research centers confirm that many parameters influence the effectiveness of the process of bleaching of kaolin by chemical methods and that control can not be exercised on all the variables involved at the same time ( $\mathrm{Lu}$ et al., 2013); the crystallinity, the percentage of impurity and size average particle are some of the variables that deeply influence the set of chemical and electrochemical reactions resulting from the addition of the reducing agent; low crystallinity and very fine clay particles and pollutants size slow decomposition of the reducing agent; the increase in temperature increases the decay rate, the reduction potential and solubilization of iron (Clark et al., 1962; Conley and Lloyd, 1970; Lu et al., 2013).

In each case has been raised a solution with little or no knowledge in the microstructure, the preferential reaction zones in the structure of kaolinite and the nature of interaccion-energia of adsorption and desorption between pollutant species of color and the surface of kaolinite an explanation for this, lies in the low efficiency as low-scale measure of some conventional techniques of physicochemical characterization as it is the case of the study of impurities of iron in kaolin by diffraction of $\mathrm{X}$-rays in powder and spectroscopic methods (Deal and Grove, 1965). 


\section{J. Eng. Applied Sci., 15 (5): 1082-1088, 2020}

To characterize, develop and refine the applications of this mineral, it is necessary to know both its structure and physicochemical and mechanical properties, it is still necessary to qualify and quantify the characteristics of the link between the mineral kaolinite and color pollutant compounds in this context, theoretical and computational physical chemistry provides a useful way to study these compounds in a rigorous manner without the limitations of some experimental methodologies in this way and as a first approach to the study of the structure of the minerals present in the selected kaolins Union (Antioquia), Colombia then show the results of experimental and computational study of the structural properties of kaolinite in Kaolin selected samples of the Union (Antioquia) and possible local phenomena in the structure. The study of physical and chemical variables that governs the structure of kaolinite are of utmost importance for phenomenological understanding and framing a scene of future work studies grounded in the field of hydro-electrometallurgy, solid state physics and mineralogy computer with the aim of improving the processing efficiency of this and other non-metallic mineral paramount in the Colombian economy.

\section{MATERIALS AND METHODS}

Experimental methodology: Three samples of Kaolin from La Union Antioquia (Colombia) with difference in susceptibility to bleaching Table 1 was selected this property related is response to industrial chemical bleaching process under operational conditions referred in the local industry.

Each sample was dissolved in water and filtered using a No. 325 mesh ( $43 \mu \mathrm{m}$. Tyler scale) in order to isolate the larger sizes to $43 \mu \mathrm{m}$, composed mainly by quartz and other large mineralogical species of interest in this kind of study. Nominal size particles $4 \mu \mathrm{m}$ were dried at room temperature after being passed by press filter, then the chemical composition of each sample was measured by X-Ray Fluorescence (XRF) using X-ray spectrometer PHILIPS PW 2400. The mineralogical composition was measured using a X-ray diffractometer Panalytical X'Pert PRO MPD with $\mathrm{Cu}$ anode and Ni filter, the oxidation states of iron were students using Mossbauer spectroscopy and finally the whiteness index was calculated measuring the reflectance spectrum in each sample using a spectrophotometer Microflash 45.

Computational methodology: To study the physical 42 properties of Kaolin, we have calculated the total energy as a function of the unit cell volume $\mathrm{E}=\mathrm{E}(\Omega)$ by fully relaxing the ionic positions and the lattice shape for each calculated volume. We have fitted the calculated data to a polynomial Eulerian strain Birch-Murnaghan $\lim _{n \rightarrow \infty}(1+1 / n)^{n}$ Equation of State (EOS) of fourth order
Table 1: Sample study

\begin{tabular}{ll}
\hline Samples & Properties \\
\hline A & Low whiteness \\
B & Medium whiteness \\
C & High whiteness \\
\hline
\end{tabular}

and extracted the equilibrium Volume $\left(\mathrm{V}_{\mathrm{o}}\right)$, the bulk modulus $(\mathrm{K})$ and its derivatives (Otero-de-la-Roza and Luana, 2011; Otero-de-la-Roza et al., 2011). All total energy, ionic forces and stress tensor components have been calculated via. Density Functional Theory (DFT). We have used for the exchange-correlation functional the generalized gradient approximation with a new parameterization, specially, targeted for solids (PBEsol) (Perdew et al., 2008). The Kohn-Sham equations are solved by the Projector Augmented Wave (PAW) method as implemented in the VASP code (Kresse and Joubert, 1999; Kresse and Furthmuller, 1996; Perdew et al., 2008). The PAW atomic reference configurations are: $3 \mathrm{~s}^{2} 3 \mathrm{p}^{2}$ for $\mathrm{Si}, 3 \mathrm{~s}^{1} 3 \mathrm{p}^{1}$ for $\mathrm{Al}, 2 \mathrm{~s}^{2} 2 \mathrm{p}^{4}$ for $\mathrm{O}$ and $1 \mathrm{~s}^{1}$ for $\mathrm{H}$ where only electrons treated as valence electrons are explicitly enumerated. The energy cut-off in the plane waves expansion is $500 \mathrm{eV}$. All structural parameters for each calculated volume have been optimized by simultaneously minimizing all atomic forces and stress tensor components via. a conjugate gradient algorithm. Brillouin-zone integration has been performed on a Monkhorst-Pack k-mesh with a Gaussian broadening of $0.01 \mathrm{eV}$ for relaxation (ionic forces are converged to $1 \mathrm{meV} / \AA$ ) and $\mathrm{a}$-centered $\mathrm{k}$-mesh using the tetrahedron method including Blochl corrections for the calculation of the total energy (this is converged to $1 \mathrm{meV} /$ formula unit) (Fachinger et al., 2006).

The calculation of the optical properties associated with the inter-band transitions are done by means of the imaginary part of the frequency dependent dielectric tensor $\varepsilon^{(2)}(\mathrm{q}, \omega)$ in the long-wavelength limit $\vec{q} \rightarrow 0$, using the methodology developed for the PAW method (Gajdos et al., 2006). The $3 \times 3$ Cartesian tensor $\varepsilon^{(2)}{ }_{\alpha \beta}(\omega)$ is given by the following equation:

$$
\begin{aligned}
& \varepsilon_{\alpha, \beta}^{(2)}(\omega)=\frac{4 \pi^{2} \mathrm{e}^{2}}{\Omega_{0}} \lim _{q \rightarrow \infty} \frac{1}{\mathrm{q}^{2}} \sum_{c, \mathrm{v}, \mathrm{k}} 2 \mathrm{w}_{\overrightarrow{\mathrm{k}}} \delta\left(\epsilon_{c \overrightarrow{\mathrm{k}}}-\epsilon_{\vec{v} \overrightarrow{\mathrm{k}}}-\omega\right) \times
\end{aligned}
$$

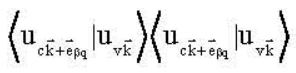

Where:

$\begin{array}{ll}\mathrm{e} & : \text { The electron charge } \\ \overrightarrow{\mathrm{q}} & \vdots \text { Denotes the Bloch vector of the incident wave } \\ \omega_{\mathrm{k}} & : \text { The } \overrightarrow{\mathrm{k}} \text {-point weights defined such that they } \\ & \text { sum to } 1 \\ \mathrm{v} \text { and } \mathrm{c}: & \begin{array}{l}\text { Sub index denote valence and conduction band } \\ \text { states, respectively }\end{array} \\ \epsilon_{\mathrm{v}(\mathrm{c}) \overrightarrow{\mathrm{k}}} & : \text { The Kohn-Sham eigenvalues } \\ 0 & \vdots \text { The frequency } \\ \mathrm{u} & \vdots \text { The wave functions } \\ \overrightarrow{\mathrm{e}}_{\mathrm{pq}} & : \text { The unit vectors for the three Cartesian } \\ & \text { directions }\end{array}$


The real part of the frequency dependent dielectric tensor is obtained from the imaginary part through the Kramers-Kroning relationship:

$$
\varepsilon_{\alpha \beta}^{(1)}(\omega)=1+\frac{2}{\pi} \mathrm{P} \int_{0}^{\infty} \mathrm{d} \omega^{\prime} \frac{\varepsilon_{\alpha \beta}^{(2)}\left(\omega^{\prime}\right) \omega^{\prime}}{\omega^{2}-\omega^{2}}
$$

where, $\mathrm{P}$ represents the principal value of the Cauchy's integral. From the knowledge of the real and imaginary parts of the dielectric tensor we have derived the generalized refractive index:

$$
\overrightarrow{\mathrm{n}}(\omega)=\sqrt{\varepsilon(\omega)}=\mathrm{n}(\omega)+\mathrm{ik}(\omega)
$$

where the real part is known as the refractive index and the imaginary part is called the extinction coefficient. Considering that the $\mathrm{n}$ dielectric tensor is a complex quantity, we explicitly calculated the refractive index $n$ and extinction coefficient $\mathrm{k}$ as follows:

$$
\begin{aligned}
& \mathrm{n}(\omega)=\frac{1}{\sqrt{2}}\left\{\left[\left(\varepsilon^{(1)}\right)^{2}+\left(\varepsilon^{(2)}\right)^{2}\right]^{\frac{1}{2}}+\varepsilon^{(1)}\right\}^{\frac{1}{2}} \\
& \mathrm{k}(\omega)=\frac{1}{\sqrt{2}}\left\{\left[\left(\varepsilon^{(1)}\right)^{2}+\left(\varepsilon^{(2)}\right)^{2}\right]^{\frac{1}{2}}+\varepsilon^{(1)}\right\}^{\frac{1}{2}}
\end{aligned}
$$

In $\mathrm{Eq}, \boldsymbol{\varepsilon}^{(1)}$ and $\boldsymbol{\varepsilon}^{(2)}$ represent the average of the real and imaginary parts of the dielectric tensor, respectively. Once known $\mathrm{n}$ and $\mathrm{k}$, we calculated the transmittance. Finally, since in high-dielectric materials the large dielectric static constant, $\varepsilon(0)$ is mostly dominated by the ionic contribution, we have also calculated the low frequency dielectric tensor $\varepsilon_{\omega}=0$ through density functional perturbation theory (Gajdos et al., 2006).

\section{RESULTS AND DISCUSSION}

X-Ray Fluorescence (XRF): The weight percent of each element present in the samples were obtained, the results are shown in Table 2. It is very important to consider the differences in XRF iron $\left(\mathrm{Fe}_{2} \mathrm{O}_{3}\right)$ present in all samples. Sample C, low susceptibility kaolin, showed the highest iron content $(1.33 \%)$ while in the opposite case, the sample $B$, high susceptibility kaolin, showed less iron contamination $(1.2 \%)$, not least is the small amount of
Titanium $\left(\mathrm{TiO}_{2}\right)$ and therefore, the sign of its little contribution as a color contaminant. Furthermore, no significant differences are in Silicon $\left(\mathrm{SiO}_{2}\right)$ and $\left(\mathrm{Al}_{2} \mathrm{O}_{3}\right)$ total average and as expected these are the common elements in the samples, putting kaolinite an aluminosilicate hydrated as predominant mineral, confirmed by the XRD patterns. The PPI measured in each sample, reveal a low volatile organic and inorganic compounds, besides, no substantial differences are between samples.

X-Ray Diffraction (XRD): The XRD equipment used in this study has a generator of $\mathrm{Cu} \mathrm{K} \alpha$ X-rays with wavelength $\lambda$ of $1.5406 \AA$ and the results were obtained under conditions of grazing incidence angle of $3^{\circ}, 2 \Theta$ range of $2-70^{\circ}$, increase of $0.02^{\circ}$ and $2 \mathrm{sec} /$ step speed with the aim of observing the phases present and crystallographic orientations. The X-ray diffraction patterns are shown in Fig. 1 and 2 and identified mineralogy species listed in Table 3 :

The results show a highly crystallinity and relative abundance of kaolinite $\mathrm{Al}_{2} \mathrm{Si}_{2} \mathrm{O}_{5}(\mathrm{OH})_{4}$ with less important species as muscovite $\mathrm{KAl}_{3} \mathrm{SiO}_{10}(\mathrm{OH})_{2}$ and quartz $\left(\mathrm{SiO}_{2}\right)$. While Muscovite can get to play an unfavorable role in bleaching kaolin was not possible in this first inspection the identification of hematite and/or goethite, responsible for unwanted coloration kaolin raw materials, one of the answers to this problem is the low amount of total iron as measured by X-Ray Fluorescence (XRF) revealed an average in the study samples of $1.26 \%$ by weight. On the other hand, an inspection of these diffraction patterns reveal no difference in crystallinity between samples for that reason, this is not an influential parameter in the sensitivities above mentioned.

Whiteness index related to the total iron content in each sample: Starting spectrograms obtained using a reflectance spectrophotometer with D45 standard illuminant and adapting these results with ASTM E313-05 were calculated CIELAB colorimetric coordinates. Table 4 lists the percentage of whiteness $(\% \mathrm{~W})$ and the total iron content in each sample. The iron content and whiteness index in the samples are inversely related variables, namely increasing of iron in a sample of

\begin{tabular}{|c|c|c|c|c|c|c|c|c|c|c|c|c|}
\hline Samples & $\mathrm{SiO}_{2}$ & $\mathrm{Al}_{2} \mathrm{O}_{3}$ & $\mathrm{Fe}_{2} \mathrm{O}_{3}$ & $\mathrm{TiO}_{2}$ & $\mathrm{CaO}$ & $\mathrm{MgO}$ & $\mathrm{Na}_{2} \mathrm{O}$ & $\mathrm{K}_{2} \mathrm{O}$ & $\mathrm{BaO}$ & $\mathrm{P}_{2} \mathrm{O}_{5}$ & $\mathrm{SO}_{3}$ & PPI de $100-1000^{\circ} \mathrm{C}$ \\
\hline $\mathrm{A}$ & 46.02 & 36.50 & 2.60 & 0.520 & $<\mathrm{LD}$ & 0.16 & ND & 0.29 & 0.033 & 0.018 & 0.033 & 13.8 \\
\hline B & 46.82 & 37.26 & 1.27 & 0.493 & $\mathrm{ND}$ & 0.08 & $\mathrm{ND}$ & 0.27 & 0.035 & 0.020 & 0.030 & 13.8 \\
\hline $\mathrm{C}$ & 46.38 & 37.59 & 1.10 & 0.580 & 0.009 & 0.06 & ND & 0.44 & 0.033 & 0.010 & 0.020 & 13.8 \\
\hline
\end{tabular}
kaolin implies lower whiteness index.

Mossbauer spectroscopy: The Mossbauer spectrum was adequately adjusted with two doublets (paramagnetic 


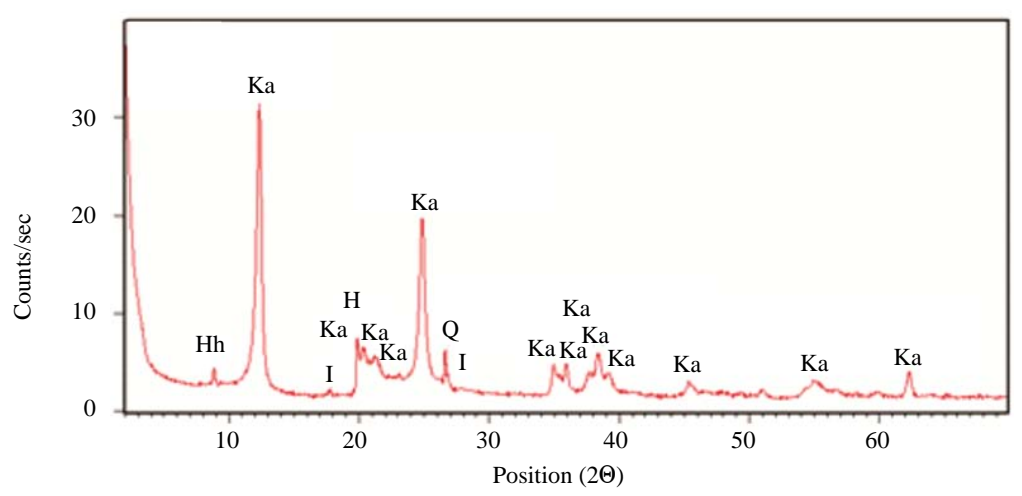

Fig. 1: $\mathrm{XRD}$, sample $\mathrm{C}$

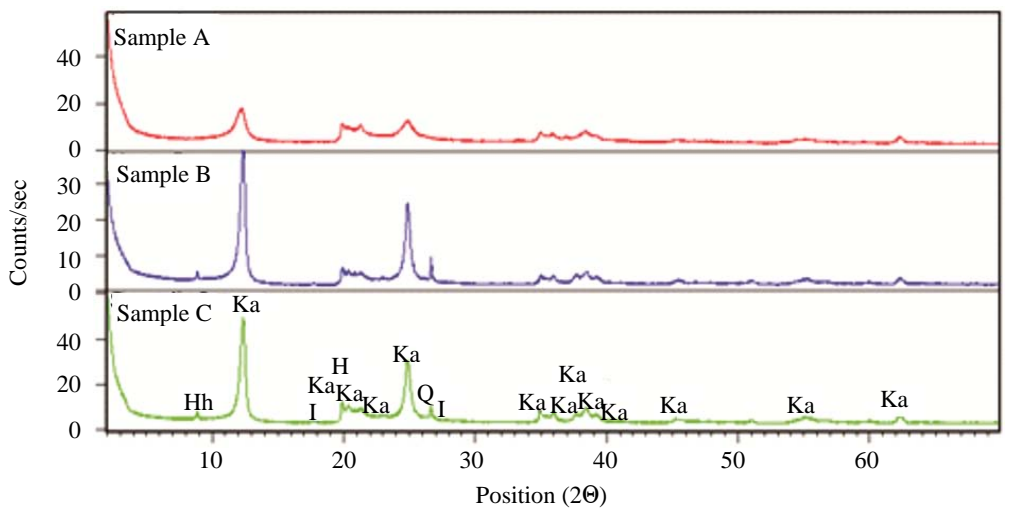

Fig. 2: $\mathrm{XRD}$ in the samples $\mathrm{A}, \mathrm{B}$ and $\mathrm{C}$

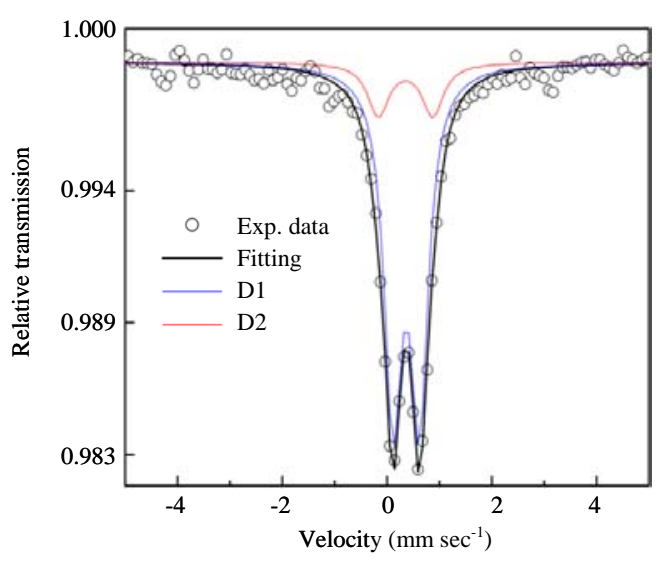

Fig. 3: Mossbauer spectroscopy in the study sample

component) which exhibit considerable symmetry and there is no evidence of any magnetic component (sextet) within the detection limit of the technique (D1 and D2 in Fig. 3). The hyperfine parameters (isomeric deviation $0.38 \mathrm{~mm}^{-1} \mathrm{sec}$ ) obtained from the adjustment suggest that in the sample there is only $\mathrm{Fe}$ in the $3+$ state, most likely high spin in an octahedral environment whose different
Table 3: Kaolin minerals

\begin{tabular}{|c|c|c|}
\hline Peak & Description & Chemical notation \\
\hline$\overline{\mathrm{Ka}}$ & Kaolinite & $\mathrm{Al}_{2} \mathrm{Si}_{2} \mathrm{O}_{5}(\mathrm{OH})_{4}$ \\
\hline I & Muscovite & $\mathrm{KAl}_{3} \mathrm{Si}_{3} \mathrm{O}_{10}(\mathrm{OH})_{2}$ \\
\hline Q & Quartz & $\mathrm{SiO}_{2}$ \\
\hline $\mathrm{Hh}$ & Hydrate halloysite $(10 \AA)$ & $\mathrm{Al}_{2} \mathrm{Si}_{2} \mathrm{O}_{5}(\mathrm{OH})_{4} 2 \mathrm{H}_{2} \mathrm{O}$ \\
\hline$\underline{\mathrm{H}}$ & Dehydrate halloysite $(7 \AA)$ & $\mathrm{Al}_{2} \mathrm{Si}_{2} \mathrm{O}_{5}(\mathrm{OH})_{4}$ \\
\hline \multicolumn{3}{|c|}{ Table 4: Iron concentration and colorimetric analysis } \\
\hline Samples & $\left(\mathrm{Fe}_{2} \mathrm{O}_{2}\right) \mathrm{Fe} \%$ & Whiteness (W\%) \\
\hline A & 2.60 & 32.77 \\
\hline B & 1.27 & 43.44 \\
\hline$\underline{\mathrm{C}}$ & 1.10 & 51.18 \\
\hline
\end{tabular}

values of the quadrupole splitting suggest that there are two types of $\mathrm{Fe}^{3+}$ in different chemical environment or with different coordination number. The double with less quadrupole splitting $\left(0.51 \mathrm{~mm}^{-1} \mathrm{sec}\right)$ can be attributed to $\mathrm{Fe}^{3+}$ ions surrounded by $\mathrm{O}^{2-}$ in an octaedral environment very little distorted referring to a phase of $\mathrm{Fe}$ proper while the double with greater quadrupole splitting $\left(1.04 \mathrm{~mm}^{-1} \mathrm{sec}\right)$ could refer to $\mathrm{Fe}^{3+}$ in a very distorted environment which could be located on the surface where there are more chances finding these defects or distortions of the octahedron (Chandrasekhar and Ramaswamy, 2002, 2006; Chandrasekhar and Ramaswamy, 2002). 


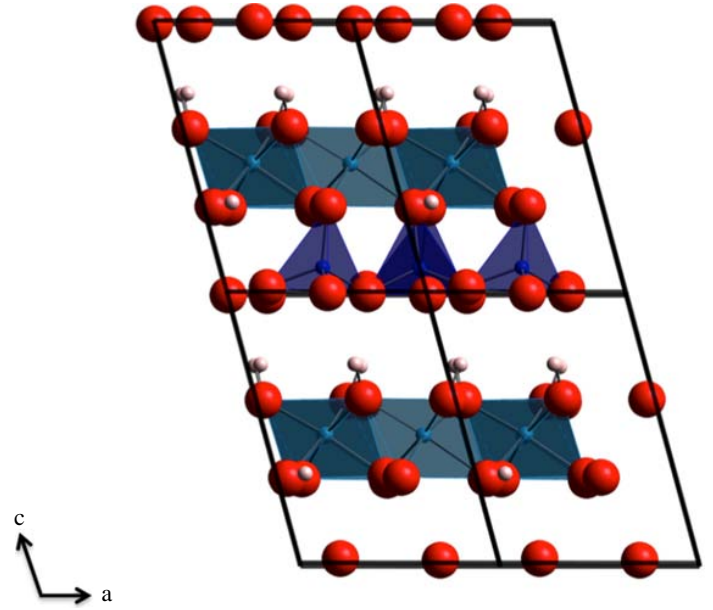

Fig. 4: Computational model. Crystalline structure of kaolinite

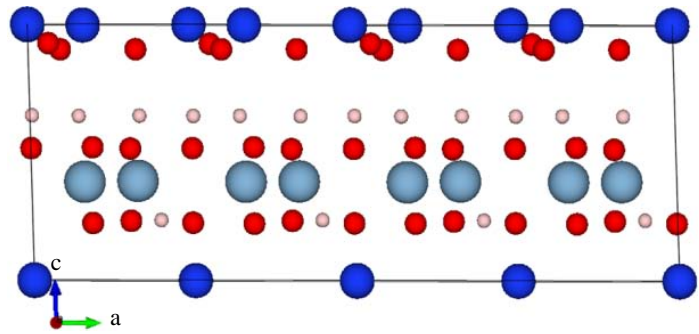

Fig. 5: Computational model. Crystalline structure of kaolinite

Table 5: Parameters in the Mossbuer spectrum analysis

\begin{tabular}{lccccl}
\hline & $\delta$ & $\Delta$ & $\Gamma$ & $\mathrm{A}$ & \\
Component & $\left(\mathrm{mm} \mathrm{sec}^{-1}\right)$ & $\left(\mathrm{mm} \mathrm{sec}^{-1}\right)$ & $\left(\mathrm{mm} \mathrm{sec}^{-1}\right)$ & $(\%)$ & Valence \\
\hline D1 & 0.38 & 0.51 & 0.20 & 84 & $\mathrm{Fe}^{3+}$ \\
D2 & 0.35 & 1.04 & 0.24 & 16 & $\mathrm{Fe}^{3+}$ distors \\
\hline
\end{tabular}

Estimated errors are of about $\pm 0.02 \mathrm{~mm} \mathrm{sec}^{-1}$ for the isomer shift, $\delta$, the quadrupole splitting, $\Delta$ and the linewidth, $\Gamma$ and of about $\pm 2 \%$ for the relative area, A. D1 and D2 are doublet 1 , doublet 2 and respectively, Table 5 shows these results (Blochl, 1994).

Theoretical and computational results: We use the experimental results of the previous stage as initial data for the theoretical and computational model (the network parameters of the modeled mineralogical species are presented in Table 6). From these data, we constructed the computational model of the crystalline structural of kaolinite (Fig. 4 and 5), the equation of states of the minerals nacrita, kaolinite, dickita and halloysite (Fig. 6), for these minerals we also estimate the equilibrium Volume $\left(\mathrm{V}_{\mathrm{o}}\right)$, the comprehension module $\left(\mathrm{B}_{\mathrm{o}}\right)$ and its first derivative as shown in Table 7.

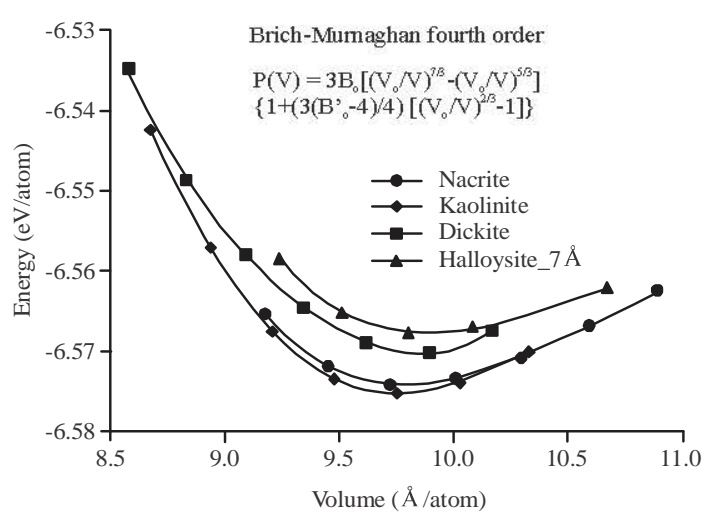

Fig. 6: Equation of states of minerals in the kaolin

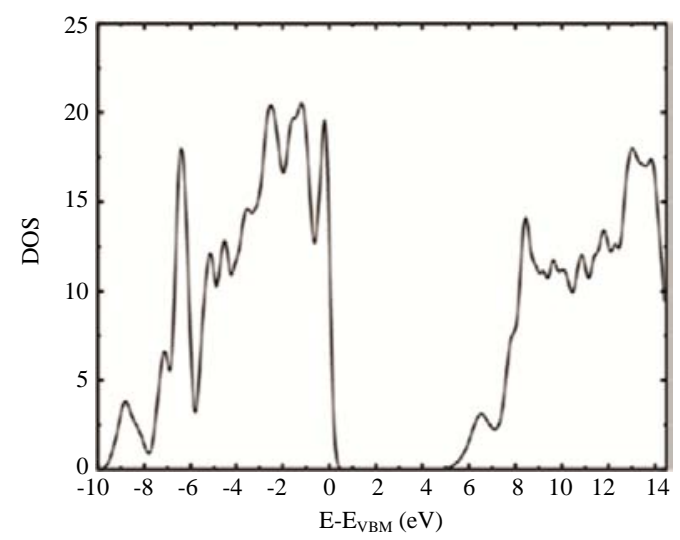

Fig. 7: Density of States (DOS) from kaolinite

Table 6: Network parameters of the main minerals in kaolins identified using DRX and used in theoretical and computational modeling

\begin{tabular}{lcc}
\hline Crystalline properties & Kaolinite & Halloysite (7A) \\
\hline Network parameters & Triclinic & Monclinic \\
\hline a & 5.16 & 5.14 \\
$\mathrm{~b}$ & 8.95 & 8.90 \\
$\mathrm{c}$ & 7.40 & 7.21 \\
$\alpha$ & 91.70 & 90.00 \\
$\beta$ & 104.86 & 99.70 \\
$\gamma$ & 89.82 & 90.00 \\
\hline
\end{tabular}

Table 7: Equilibrium Volume $\left(\mathrm{V}_{0}\right)$, compression module $\left(\mathrm{B}_{0}\right)$ and its first derivative

\begin{tabular}{lllr}
\hline Fase & $\mathrm{V}_{0}\left(\AA^{3}\right)$ & $\mathrm{B}_{0}(\mathrm{GPa})$ & \multicolumn{1}{c}{$\mathrm{B}_{\circ}{ }^{\prime}$} \\
\hline Nacrtite & 9.7427 & 51.6063 & 12.3382 \\
Kaolinite & 9.6914 & 62.2697 & 12.4613 \\
Dickite & 9.2111 & 45.1483 & 0.7828 \\
Halloysite $7 \AA^{3}$ & 9.8389 & 40.0572 & 17.8651 \\
\hline
\end{tabular}

On the other hand, we calculate the density diagram of the kaolinite states Fig. 7 and the real and imaginary fractions of the dielectric matrix we also Fig. 8, calculate the refractive index Fig. 9 and the dielectric constants matrix Fig. 10. Finally, we estimate the trasminatance and reflectivity spectra for kaolinite and the results are shown in Fig. 11. 


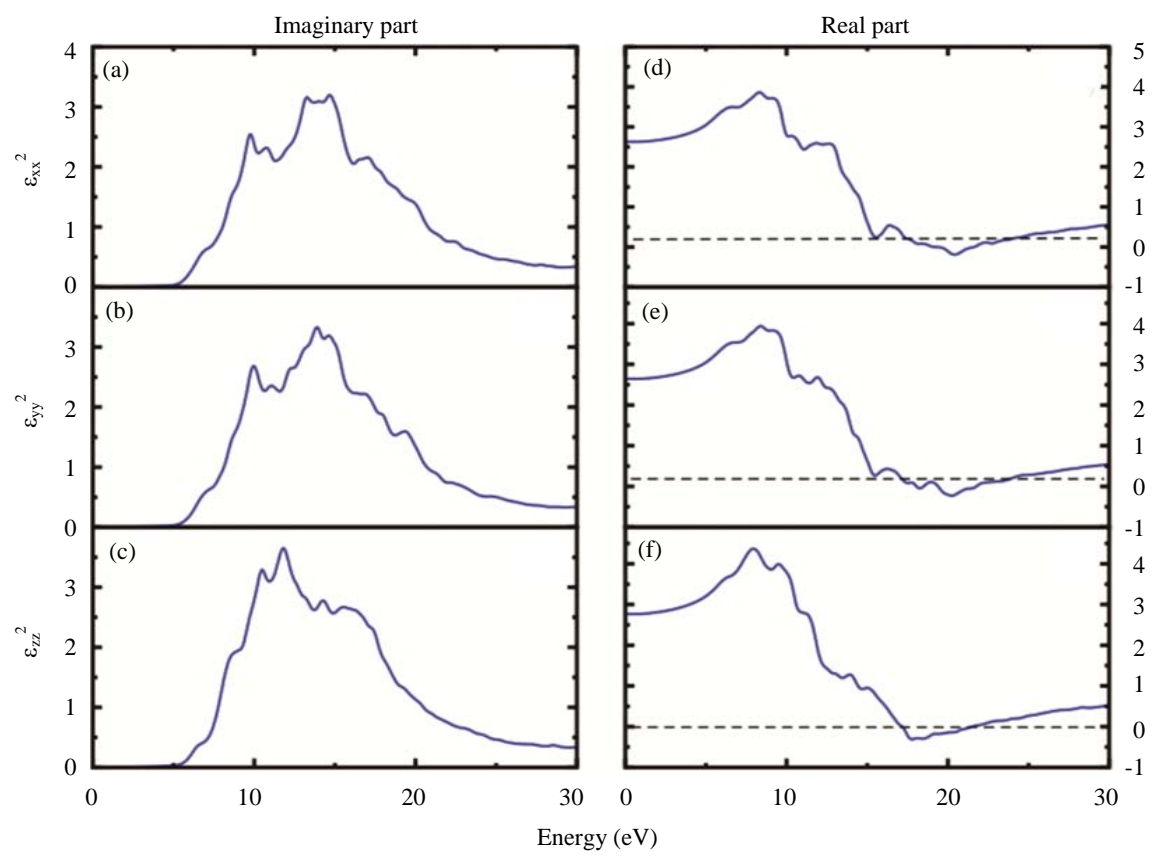

Fig. 8(a-f): Dielectric matrix

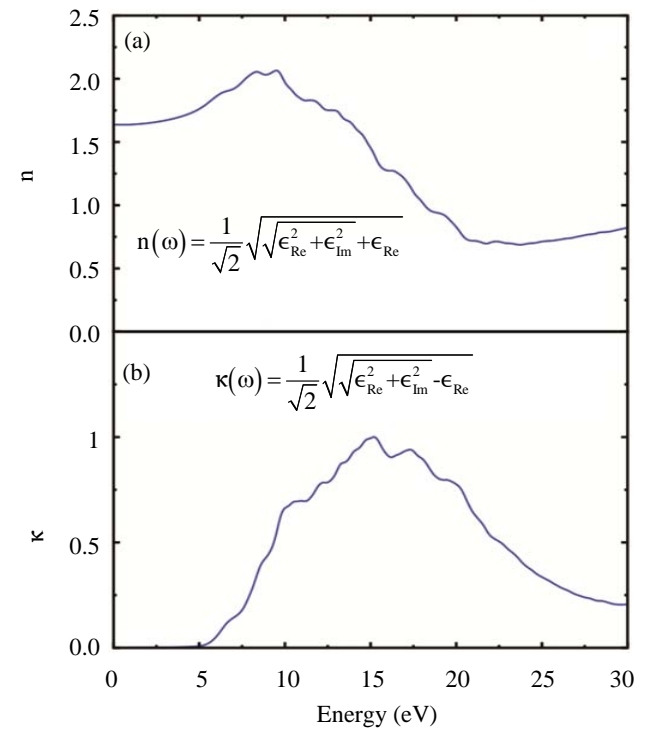

Fig. 9(a,b): Refractive index

$$
\begin{aligned}
\epsilon_{\omega \rightarrow \infty} & =\left(\begin{array}{ccc}
2.670 & 0.012 & -0.004 \\
0.012 & 2.685 & -0.006 \\
-0.004 & -0.006 & 2.803
\end{array}\right) \\
\epsilon_{\omega \rightarrow 0} & =\left(\begin{array}{ccc}
3.773 & 0.128 & -0.108 \\
0.128 & 3.798 & -0.185 \\
-0.108 & -0.185 & 2.482
\end{array}\right)
\end{aligned}
$$

Fig. 10: Dielectric constant

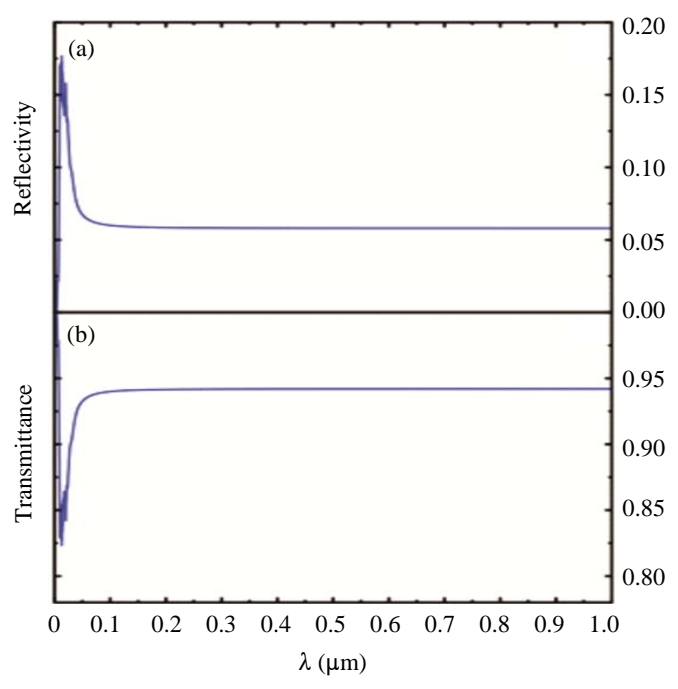

Fig. 11(a, b): (a) Reflectivity and (b) transmittance

\section{CONCLUSION}

The bleaching susceptibility is defined like the kaolin answer to the bleaching industrial process. The bleaching susceptibility depends of crystallinity differences in kaolin and iron concentration. Each sample showed a different crystallinity value. The kaolin bleaching process could be interpreted like an iron electrochemical selective process. It is possible to think in future works in order to increase the efficiency of bleaching process. 
The theoretical and computational results, largely conform to the experimental results, therefore are outlined as a good methodology to understand the phenomenology in the benefit of non-metallic minerals and increase the efficiency in its processing.

\section{ACKNOWLEDGEMENT}

We thank the Institute of Minerals CIMEX of the Universidad Nacional de Colombia, the Instituto Tecnológico Metropolitano de Medellín (ITM) and the company Sumicol S.A., for the budget, materials and supplies needed to develop this research.

\section{REFERENCES}

Benea, M. and M. Gorea, 2004. Mineralogy and technological properties of some kaolin types used in the ceramic industry. Stud. UBB. Geologia, 49: 33-39.

Blochl, P.E., 1994. Projector augmented-wave method. Phys. Rev. B., Vol. 50, No. 24. 10.1103/PhysRevB.50.17953

Chandrasekhar, S. and S. Ramaswamy, 2002. Influence of mineral impurities on the properties of kaolin and its thermally treated products. Applied Clay Sci., 21: $133-142$.

Chandrasekhar, S. and S. Ramaswamy, 2006. Iron minerals and their influence on the optical properties of two Indian kaolins. Applied Clay Sci., 33: 269-277.

Clark, T., R. Woodley and D. De Halas, 1962. Gas-Graphite Systems. In: Nuclear Graphite, Nightingale, R.E. (Ed.). Academic Press, Cambridge, Massachusetts, USA., pp: 387-389.

Conley, R.F. and M.K. Lloyd, 1970. Improvement of iron leaching in clays: Optimizing processing parameters in Sodium Dithionite reduction. Ind. Eng. Chem. Process Des. Dev., 9: 595-601.

Deal, B.E. and A.S. Grove, 1965. General relationship for the thermal oxidation of silicon. J. Applied Phys., 36: 3770-3778.
Fachinger, J., M. Den Exter, B. Grambow, S. Holgersson, C. Landesman, M. Titov and T. Podruhzina, 2006. Behaviour of spent HTR fuel elements in aquatic phases of repository host rock formations. Nucl. Eng. Des., 236: 543-554.

Gajdos, M., K. Hummer, G. Kresse, J. Furthmuller and F. Bechstedt, 2006. Linear optical properties in the projector-augmented wave methodology. Phys. Rev. B., Vol. 73,

Gonzalez, J.A. and M.D.C. Ruiz, 2006. Bleaching of kaolins and clays by chlorination of iron and titanium. Applied Clay Sci., 33: 219-229.

INL., 2009. Deep-burn project: Annual report for 2009. Idaho National Laboratory, Idaho Falls, Idaho.

Kresse, G. and D. Joubert, 1999. From ultrasoft pseudopotentials to the projector augmented-wave method. Phys. Rev. B., 59: 1758-1775.

Kresse, G. and J. Furthmuller, 1996. Efficient iterative schemes for $\mathrm{AB}$ initio total-energy calculations using a plane-wave basis set. Phys. Rev. B., 54: 11169-11186.

Lu, C.H., M. Fang, H.X. Lai, L.Q. Huang and J. Chen et al., 2013. Research on the whitening mechanism of Kaolin by chemical bleaching and calcining. Applied Mech. Mater., 420: 254-258.

Murray, H.H., 1963. Industrial applications of Kaolin. Proceedings of the 10th International Conference on Clays and Clay Minerals, October 14-15, 1963, Macmillan, New York, USA., pp: 291-298.

Otero-de-la-Roza, A. and V. Luana, 2011. Gibbs2: A new version of the quasi-harmonic model code. I. Robust treatment of the static data. Comput. Phys. Commun., 182: 1708-1720.

Otero-de-la-Roza, A., D. Abbasi-Perez and V. Luana, 2011. Gibbs2: A new version of the quasiharmonic model code. II. Models for solid-state thermodynamics, features and implementation. Comput. Phys. Commun., 182: 2232-2248.

Perdew, J.P., A. Ruzsinszky, G.I. Csonka, O.A. Vydrov and G.E. Scuseria et al., 2008. Restoring the density-gradient expansion for exchange in solids and surfaces. Phys. Rev. Lett., Vol. 100, No. 13. 10.1103/PhysRevLett.100.136406. 